\title{
In utero pesticides exposure and generation of acute myeloid leukemia associated translocation (8; 2I)
}

\begin{abstract}
This study aimed to detect the relationship between prenatal exposure to organophosphate and organo chlorine pesticides and development of translocation $(8 ; 21)$; in an Egyptian population between 2010-2012. Malathion, Diazinon, DDT, and Lindane were detected in meconium by gas chromatography- mass spectrometry (GC-MS). T $(8 ; 21)$ was detected by RT-PCR on RNA extracted from cord blood. Thirty eight $(20 \%)$ out of 190 of the cord blood samples were positive for $\mathrm{t}(8 ; 21)$. Chi square tests were used to assess differences in the frequency of pesticide exposure in $\mathrm{t}(8 ; 21)$ carriers vs. non carriers and the risk estimates were assessed using binary logistic regression. The frequency of prenatal Malathion exposure was 61 , and $36 \%$ in newborn t $(8 ; 21)$ carriers and non-carriers, respectively, (OR $2.78,95 \%$ CI 1.34-5.77). The frequency of exposure was 58 and $41 \%$ for Diazinon (OR $1.94,95 \%$ CI $0.95-3.99$ ), 79 and $51 \%$ for DDT (OR 3.55, 95\%CI 1.53-8.26) and 55 and $49 \%$ for Lindane (OR 1.32, 95\% CI 0.63-2.66). Rural residents showed a higher frequency of translocation than the urban; $23.6 \%$ of the rural were carriers versus only $3 \%$ forthe urban, $(\mathrm{P}=0.007)$. Rural residents showed a 10 fold increased risk to develop the fusion Oncogene. Prenatal exposure to organophosphate and organochlorine is potentially related to the generation of $\mathrm{t}(8 ; 21)$ in the cord blood of apparently healthy newborns. Residing in rural areas imparts a higher risk for carrying such translocation.
\end{abstract}

Keywords: prenatal, organophosphate, organochlorine, gc-ms, leukemia, translocation $(8 ; 21)$
Volume 2 Issue 3 - 2016

\author{
Mona AH El Baz,' Sahar EM El Deek,' Ayat A \\ Sayed,' Ahmed F Amin ${ }^{2}$ \\ 'Department of Medical Biochemistry, Assiut University, Egypt \\ ${ }^{2}$ Women's Health Hospital, Assiut University, Egypt
}

\begin{abstract}
Correspondence: Mona AH El Baz, Department of Medica Biochemistry, Faculty of Medicine, Assiut University, Assiut 7I5I5, Egypt, Tel +201005800409, Fax +208823337878, Email monaelbaz।@gmail.com
\end{abstract}

Received: October 28, 2016 | Published: November 28, 2016

\section{Introduction}

Acute myeloid leukemia (AML) constitutes about 20\% of childhood leukemia, representing the second most common malignancy during the first year of life. It is the leading cause of death due to neoplasm in early childhood. ${ }^{1}$ Despite intense investigation, decoding the molecular abnormalities of AML is lacking. Early twin studies grounded for the fetal genetic origin of leukemia. ${ }^{2-4}$ Indeed, the presence of chromosomal fusion and sequence rearrangements in archived neonatal heel-prick spots of children who later developed leukemia also supports the theory of its prenatal origin. ${ }^{2-4}$ Translocation $(8 ; 21)$ is one of the most common chromosomal translocations; its frequency ranged from $20 \%{ }^{5}$ to $30 \%{ }^{6}$ in AML cases. The translocation results in fusion of $5^{\circ}$ end of exon 2 of the ETO gene on chromosome 8 with $3^{\prime}$ end of exon 5 of AML1 gene on chromosome 21, producing a novel chimeric gene, AML1-ETO. AML1-ETO fusion protein is a multifunctional cellular protein that affects cellular growth and differentiation, as well as apoptosis and self-renewal potential. ${ }^{7}$ Initiation of the first step of leukemogenesis probably occurs via transcriptional repression/activation of AML1 target genes, many of which are key players in the differentiation of myeloid and lymphoid linages. It was found that the fusion gene disrupts the site for core-binding factor (CBF), an essential transcription factor for normal hemopoietic cell differentiation. ${ }^{8}$ This $t(8 ; 21)$ translocation is suggested to occur during early fetal hemopoietic ending up with a group of long lived cells that may or may not progress to overt leukemia later in life depending upon secondary genetic events, with a latency period that may exceed 10 years. ${ }^{4-10}$ Beside molecular-genetic aberrations, environmental toxins have also been accused for development chromosomal translocation associated with hematological malignancy. In fact, interaction between environmental and molecular factors seems obligatory for the cells to achieve the final malignant phenotype. Many studies have reported an association between residential and occupational pesticide exposure by pregnant mothers, fathers and children and development of leukemia. ${ }^{11-13}$ Therefore, combined molecular and environmental studies are needed to better elucidate the bio-molecular basis of leukemia associated traits and chromosomal translocation, and hence reduce its incidence, morbidity and mortality outcome. ${ }^{10}$ The present study was set to detect $\mathrm{t}(8 ; 21)$ translocation in umbilical cord blood samples from neonates as in utero primary molecular hit in the pathway of childhood leukemia in apparently healthy neonates and to delineate the relationship between generation of this translocation and prenatal pesticide exposure. Four pesticides were studied including Malathion and Diazinon as organophosphates, and DDT and Lindane as organochlorines. The choice of these four pesticides was based on their popular use in the community under investigation and their wellestablished role in cancer pathology. ${ }^{13-15}$

\section{Materials and methods}

\section{Sampling}

This study recruited 190 healthy neonates from the labor ward of the Women's Health Hospital, Assiut University, Assiut, Egypt, between March 2010 and May 2012, from which meconium and 10ml cord blood were obtained. Women's health hospital is the largest tertiary care maternity hospital in Upper Egypt. The hospital presents services to residents from both agricultural and urban regions. Out of 
1128 pregnant women from agriculture farms around Assiut, who were examined in the antenatal clinic during the study period, 582 pregnant women were eligible for the study, 226 gave consent and finally 157 completed all components of the study. Out of 253 pregnant women from the urban area who were examined in the antenatal clinic during the study period, 125 fulfilled the inclusion criteria and 87 consented, of which only 33 completed all components of the study. Mothers with chronic diseases including diabetes mellitus, hypertension, cardiac disorders, renal or hepatic diseases, anaemia, thyroid disease, and/ or pregnancy related complications were excluded. Also, smoking, chronic drug intake, delivery of preterm baby, or a baby with congenital and/or suspected chromosomal abnormalities (as shown by physical examination, chromosomal charts or previous history of giving birth to offspring with chromosomal abnormalities) set the exclusion criteria. Eventually none of the parents was AML patient.

All data were collected by one of the researchers through oneto-one administered questionnaire in a private room after enrolment of women in the study. Paternal history of pesticide exposure and smoking were collected from mothers. Clinical examination and review of hospital records were performed for the mothers and neonates. Maternal data including age, occupation, and residence, fetal data, and mode of delivery, gestational age, birth weight and Apgar score were recorded.

\section{Pesticide detection}

Meconium was obtained from the diaper of the newborn babies during the 1st $24 \mathrm{hrs}$. Four pesticides were studied, Malathion and Diazinon as organophosphates, and DDT and Lindane as organochlorines. Gas chromatography/ mass spectrometry (GC-MS) from Agilent Technologies (Model 7890A) was used to quantitatively detect these pesticides after solid phase extraction from meconium according to previously described methods. ${ }^{17,18}$ Briefly, $0.5 \mathrm{~g}$ of meconium was methanol/ hexane extracted; the organic phase was kept at $-20^{\circ} \mathrm{C}$ till the time of assay. Custom Pesticides mixture in hexane was purchased from Sigma with cat. No. 45428, 36143, SZE9315X, and SZE7038X, for Malathion, Diazinon, DDT, and Lindane, respectively. Negative meconium samples and positive meconium samples spiked with serial dilution of standards of this pesticides mix were used as negative and positive controls and calibrator in the assay. DB-5ms column was used for separation of the analytes in Helium as carrier gas; detection was performed by Mass Quadruple Spectrometry detector Model 5975B. A computer data system (MSD Chem Station E.0201.1177) was used for measuring peak areas and heights. All steps are validated using reference materials; this includes linearity, range, precision, accuracy, specificity/ selectivity, limit of detection, quantitation limit and robustness. ${ }^{19}$ The linearity of the chromatographic responses of all these analytes was studied by a series of aqueous calibration standards, are extracted and analyzed at different concentrations and has given good results in the sense that they are wide ranging $(0.020-320.00 \mu \mathrm{g} / \mathrm{L})$ for OCPs and $(0.062-$ $256.00 \mu \mathrm{g} / \mathrm{L})$ for OPPs. Correlation coefficients $\left(\mathrm{r}^{2}\right)$ were higher than 0.9980 . The LOD by the empirical approach for parent compounds ranged from 0.0015 for DDT, 0.0025 for Lindane, 0.0037 for Diazinon and $0.0024 \mu \mathrm{g} / \mathrm{L}$ for Malathion.

\section{Rna extraction, rt pcr for $\mathbf{t}(\mathbf{8} ; \mathbf{2} I)$ detection}

RNA was extracted from freshly collected cord blood using QIAamp RNA blood mini kit (Qiagen) according to manufacturer's protocol. One step RT-PCR was carried out using $10 \mu 1$ of RT-PCR buffer (Qiagen), $400 \mu \mathrm{M}$ of dNTPs, $0.6 \mu \mathrm{M}$ of forward AML-1A primer (5'-CTACCGCAGCCATGAAGAACC-3') and $0.6 \mu \mathrm{M}$ of ETO-B (5'-AGAGGAAGGCCCATTGCTGAA-3'); reverse primer, ${ }^{20} 2 \mu 1$ of one step RT-PCR enzyme mix (Qiagen), $1 \mu \mathrm{g}$ RNA, and up to $50 \mu 1$ RNase free water. The reaction was carried out on T-professional thermal cycler (Biometra) according to the following cycling conditions; reverse transcription step at $50^{\circ} \mathrm{C}$ for $30 \mathrm{~min}$, initial denaturation at $95^{\circ} \mathrm{C}$ for $15 \mathrm{~min}, 40$ cycles of denaturation at $95^{\circ} \mathrm{C}$ for $40 \mathrm{sec}$, annealing at $54^{\circ} \mathrm{C}$ for $40 \mathrm{sec}$ and extension at $72^{\circ} \mathrm{C}$ for $1 \mathrm{~min}$. This was followed by final extension step at $72^{\circ} \mathrm{C}$ for $10 \mathrm{~min}$. To ensure the specificity of the product, nested PCR was conducted using $1 \mu \mathrm{l}$ from the $1 \mathrm{ST}$ round PCR product, $10 \mu \mathrm{l}$ PCR Master mix (Qiagen), $0.4 \mu \mathrm{M}$ of AML1-C forward primer; (5'-ATGACCTCAGGTTTGTCGGTCG-3') and $0.4 \mu \mathrm{M}$ of ETO-D reverse primer; (5'-TGAACTGGTTCTTGGAGCTCCT-3' ${ }^{\prime 20}$ in a total reaction volume of $20 \mu \mathrm{l}$, the same cycling conditions as the $1 \mathrm{st}$ round was applied. PCR products were electrophoresed on ethidium bromide stained $1 \%$ agarose gel in $1 \mathrm{X}$ TAE buffer and visualized by Bio Doc analyzer gel documentation system. A confirmed $\mathrm{t}(8$; 21) acute myeloid leukemia (M2 subtype) case was included as positive control. For quality control measures $10 \%$ of the samples were re-tested independently in Delta Scientifics, Alexandria, Egypt. Moreover $10 \%$ of the positive samples were confirmed by sequencing. The sequencing reaction was performed on the PCR product from the 1st round after purification using the QIAquick PCR purification kit (QIAGEN). The sequencing reaction was carried out in a $10 \mu 1$ in which $3 \mu 1$ of cleaned PCR product was mixed with $2.5 \mathrm{X}$ Big Dye 3.1 reaction mix, $5 \mathrm{x}$ big dye terminator buffer (Applied Biosystems), and $5 \mathrm{pmol}$ of the AML1-B primer. Samples were centrifuged at 5000rpm for $3 \mathrm{~min}$ through Centri-sep columns (Princeton Sepration ${ }^{\circledR}$ ). Sequencing was carried out using ABI PRISM ${ }^{\circledR} 310$ Genetic Analyzer (Applied Biosystems). Sequences were viewed by Chromas Lite V2.01 (http://www.technelysium.com.au/ chromas_lite.html). Sequence identity was confirmed by NCBI Blastn, and Blat function of the UCSC browser. As the translocation is an acquired and not an inherited genetic trait it was not investigated in any of the parents.

\section{Statistical analysis}

Data were collected, verified and analyzed using the Statistical Package for Social Sciences (SPSS version 16). The results were presented as mean \pm SEM, P value for Mann-Whitney $U$ test for continuous data. Number and percentages, $\mathrm{P}$ value for Chi-square test are presented for categorical variables. Exposed / unexposed was defined as categorical variables, when exposure was assigned by successful detection of the pesticides in meconium at or above the lower limit of detection (LOD). LOD was calculated by empirical method, described as lowest concentration that comes in consensus with GC-MS criteria previously reported by Armbruster et al. ${ }^{21}$ and by Bielawski et al. ${ }^{17}$ Combined exposure was introduced as a new categorical variable when both Malathion and DDT were at or passed the LOD. Unconditional binary logistic regression for risk estimates was applied and presented as odds ratio (OR), \% confidence interval (CI). OR ratios were adjusted for residence and pesticides exposure when both were included in the equation simultaneously. A significant $\mathrm{P}$ value was considered below 0.05 .

\section{Results}

The current study included a total of 190 subjects with mean maternal age 26.8 years. Sixty nine percent were multiparous, $23 \%$ 
were working, and $83 \%$ lived in rural areas while $17 \%$ lived in urban areas. Mean birth weight was $3097 \mathrm{~g}$ and Apgar score was $\geq 7$ in $96 \%$ of the cases, Table 1 .Thirty eight (20\%) neonates were shown to be $\mathrm{t}(8 ; 21)$ carriers, as indicated by successful amplification of 395 and $260 \mathrm{bp}$ products from cord blood using AML1-A, ETO-B as external primers, AML1-C and ETO-D as internal primer, (Figure 1). The exact identity was confirmed by sequencing a subset of the samples. The sequences included exon 2 and 3 that belong to ETO gene on chromosome 8 and exon 5 of the AML-1 gene on chromosome 21. It was $100 \%$ identical with RUNX1-RUNX1T1mRNA sequence (GenBank: JZ719066.1). The samples tested in house, the samples investigated independently by Delta Scientifics, and those confirmed by sequencing showed 100 concordance with each other. No specific impact of maternal age, parity, working status, was reported on the generation of $\mathrm{t}(8 ; 21)$ translocation $(\mathrm{P}=0.578, \mathrm{P}=0.313$ and $\mathrm{P}=0.112$, respectively). On the other hand, rural residents have shown a higher frequency of translocation than urban residents $(\mathrm{P}=0.007)$ (Table 1). Meanwhile, being a t $(8 ; 21)$ carrier did not adversely affect any of the birth outcome variables, including gestational age, type of delivery, birth weight or Apgar Score $(\mathrm{P}=0.543, \mathrm{P}=0.276, \mathrm{P}=0.246$, and $\mathrm{P}=0.191$ respectively), (Table 1 ). Of the 190 neonates, 77, 85, 108 , and 95 , were determined to be exposed to malathion, diazinon, DDT, and lindane, respectively, (Table 2). Exposure was defined by successful detection of the pesticide in meconium at or above the lower limit of detection (LOD). LOD was calculated by empirical method, described as lowest concentration that comes in consensus with GC-MS criteria previously reported by Armbruster et al., ${ }^{21}$ and by Bielawski et al. ${ }^{17}$ The frequency of prenatal pesticide exposure among newborn $\mathrm{t}(8 ; 21)$ carriers was $61 \%, 58 \%, 79 \%$ and $55 \%$ for Malathion, Diazinon, DDT and Lindane, respectively. Expectedly, the frequency of pesticide exposure was higher in translocation carriers compared to non-carriers. Malathion exposure was associated with increased risk for the generation of leukemia translocation with an OR of 2.78 (95\%CI 1.34-5.77) and $\mathrm{P}=0.006$. Of the studied pesticides, DDT was accompanied by highest risk for carrying the fusion Oncogene [OR 3.55 (95\%CI 1.53-8.26), $\mathrm{P}=0.003$ ]. Combined exposure to Malathion and DDT was reported in 73 subjects (38\%) OR was 7.07(95\%CI2.3920.89) $\mathrm{P}<0.001$, combined exposure was reported when the level of both pesticides was at or above LOD as stated in the methods section. The least risk accompanied diazinone and lindane which exposure conferred no significant risk for generation of $\mathrm{t}(8 ; 21)$ translocation; data are shown in (Table 2). The risk estimates showed no alteration / increased when the pesticides exposure was corrected for residence, (Table 2). We did not adjust for other maternal or fetal covariates as they were initially similar between both translocation carriers and noncarriers. Rural residents were more prone to carry the translocation; OR was 9.89 (95\%CI1.30-74.70) $\mathrm{P}=0.027$, the risk of carrying the translocation was more evident in rural residents when adjusted for pesticides exposure (Table 3 ). Not only the frequency of pesticide exposure was high in $\mathrm{t}(8 ; 21)$ carriers but also the levels. There were significantly high levels of Malathion, Diazinon, DDT and Lindane in $\mathrm{t}(8 ; 21)$ carriers compared to non $\mathrm{t}(8 ; 21)$ carriers $(\mathrm{P} \leq 0.001, \mathrm{P}=0.004$, $\mathrm{P}=0.001$, and $\mathrm{P}=0.04$ respectively), (Table 4 ).

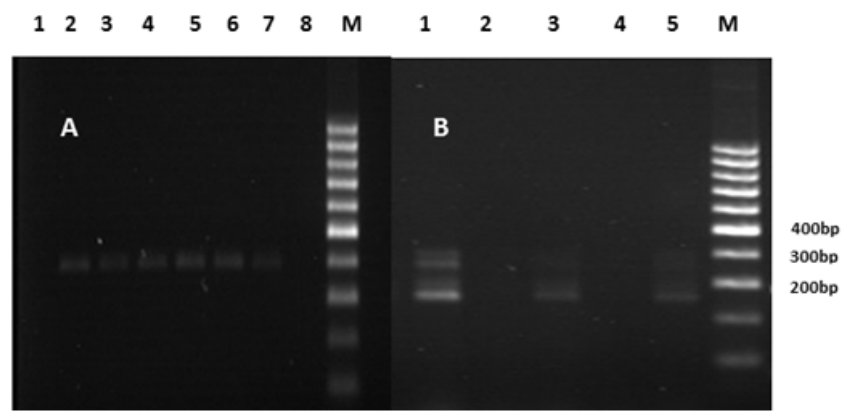

Figure I t (8:2I) translocation in cord blood.

A. Ist round PCR using AMLI-A and ETO-B primers yielding 395bp products. Lane I is RT-ve control, lane 2 is $t(8 ; 2 I)$ confirmed $t(8 ; 2 I)$ acute myeloid leukemia case positive control, lane 3-7 are representative of positive translocation in cord blood, lane 8 is representative of negative translocation in cord blood, and lane $\mathrm{M}$ is $100 \mathrm{bp}$ marker;

B. Nested PCR using AMLI-C and ETO-D primers showing 260bp. Lanes $I$ and 3 are representatives of positive translocation in cord blood, lane 2 and 4 are representative of negative translocation in cord blood, lane 5 is positive control, and lane $M$ is 100 bp marker.

Table I Fetal and maternal characteristics of $\mathrm{t}(8 ; 2 \mathrm{I})$ carriers and non-carriers

\begin{tabular}{|c|c|c|c|c|}
\hline Variables & Total $(\mathbf{N}=\mid 90)$ & $\begin{array}{l}t(8 ; 2 I) \text { Carriers } \\
(N=38)\end{array}$ & $\begin{array}{l}t(8 ; 2 I) \text { Non-Carriers } \\
(\mathrm{N}=152)\end{array}$ & $P$ value \\
\hline Maternal Age (years) & $26.8(0.46)$ & $27.3(1.14)$ & $26.6(0.5)$ & 0.578 \\
\hline \multicolumn{5}{|l|}{ Parity } \\
\hline Primiparous & $59(31 \%)$ & $10(26 \%)$ & 49 (32\%) & \multirow{2}{*}{0.313} \\
\hline Multiparous & $13 \mid(69 \%)$ & $28(74 \%)$ & $103(68 \%)$ & \\
\hline \multicolumn{5}{|l|}{ Working status } \\
\hline Yes & 43 (23\%) & $12(31 \%)$ & $31(20 \%)$ & \multirow{2}{*}{0.112} \\
\hline No & 147 (77\%) & $26(69 \%)$ & $|2|(80 \%)$ & \\
\hline \multicolumn{5}{|l|}{ Residence } \\
\hline Rural & $157(83 \%)$ & 37 (97\%) & $120(78 \%)$ & \multirow{2}{*}{0.007} \\
\hline Urban & $33(17 \%)$ & I (3\%) & $32(22 \%)$ & \\
\hline Gestational age (weeks) & $37.4(0.16)$ & $37.2(0.31)$ & $37.5(0.18)$ & 0.543 \\
\hline \multicolumn{5}{|l|}{ Type of delivery } \\
\hline Normal & 77 (40\%) & $14(37 \%)$ & $63(41 \%)$ & \multirow{2}{*}{0.276} \\
\hline Cesarean & $113(60 \%)$ & $24(63 \%)$ & 89 (59\%) & \\
\hline Birth weight (g) & $3097(44)$ & $3200(98)$ & $307 \mid(50)$ & 0.246 \\
\hline
\end{tabular}




\begin{tabular}{lllll} 
table continued... & Total $(\mathbf{N}=1 \mathbf{9 0})$ & $\begin{array}{l}\mathbf{t}(\mathbf{8} ; \mathbf{2} \mathbf{I}) \text { Carriers } \\
\mathbf{( N = 3 8 )}\end{array}$ & $\begin{array}{l}\mathbf{t ( 8 ; 2}(\mathbf{1}) \text { Non-Carriers } \\
\mathbf{( N = 1 5 2 )}\end{array}$ & P value \\
\hline Aariables & & & & \\
\hline$\geq 7$ & $183(96 \%)$ & $38(100 \%)$ & $145(95 \%)$ & 0.191 \\
$\leq 7$ & $7(4 \%)$ & $0(0 \%)$ & $7(5 \%)$ &
\end{tabular}

Categorical data are presented as number and percentage; $P$ values were calculated using Chi-squared test. Continuous data are presented as mean and SEM, $P$ value was calculated by Mann-Whitney $U$ test. $P$ values were considered significant below 0.05 .

Table 2 Frequency of prenatal exposure to pesticides among new-born $\mathrm{t}(8: 2 \mathrm{l})$ carriers and non-carriers

\begin{tabular}{|c|c|c|c|c|c|}
\hline Pesticides & $\begin{array}{l}\text { Total } \\
(\mathrm{N}=190)\end{array}$ & $\begin{array}{l}t(8 ; 2 I) \text { Carriers } \\
(N=38)\end{array}$ & $\begin{array}{l}t(8 ; 2 I) \text { Non-Carriers } \\
(N=152)\end{array}$ & $\begin{array}{l}\text { OD }(95 \% \mathrm{Cl}) \\
\text { (P-value) }\end{array}$ & $\begin{array}{l}\text { *Adjusted OD }(95 \% \mathrm{Cl}) \\
\text { (P-value) }\end{array}$ \\
\hline \multicolumn{6}{|l|}{ Malathion } \\
\hline Exposed & 77 (4I\%) & 23 (6I\%) & $54(36 \%)$ & $2.78(1.34-5.77)$ & $2.79(1.32-5.87)$ \\
\hline $\begin{array}{l}\text { Non- } \\
\text { exposed }\end{array}$ & 113 (59\%) & 15 (39\%) & $98(64 \%)$ & 0.006 & 0.007 \\
\hline \multicolumn{6}{|l|}{ Diazinon } \\
\hline Exposed & 85 (45\%) & $22(58 \%)$ & $63(41 \%)$ & $1.94(0.95-3.99)$ & $2.13(1.02-4.45)$ \\
\hline $\begin{array}{l}\text { Non- } \\
\text { exposed }\end{array}$ & 105 (55\%) & 16 (42\%) & 89 (59\%) & 0.071 & 0.044 \\
\hline \multicolumn{6}{|l|}{ DDT } \\
\hline Exposed & $108(57 \%)$ & 30 (79\%) & 78 (5।\%) & $3.55(1.53-8.26)$ & $3.44(1.46-8.08)$ \\
\hline $\begin{array}{l}\text { Non } \\
\text { exposed }\end{array}$ & $82(43 \%)$ & $8(21 \%)$ & 74 (49\%) & 0.003 & 0.005 \\
\hline \multicolumn{6}{|l|}{ Lindane } \\
\hline Exposed & 95 (50\%) & 21 (55\%) & 74 (49\%) & $1.32(0.63-2.66)$ & I.23 (0.60-2.54) \\
\hline $\begin{array}{l}\text { Non } \\
\text { exposed }\end{array}$ & 95 (50\%) & 17 (45\%) & $78(51 \%)$ & 0.468 & 0.581 \\
\hline
\end{tabular}

Exposure was defined by successful detection of the pesticides in meconium at or above the lower limit of detection (LOD). LOD was calculated by empirical method, described as lowest concentration that comes in consensus with GC-MS criteria previously reported. 18,21 Data are presented as number and percentage. Unconditional binary logistic regression for risk estimates was applied and presented as odds ratio (OR), $95 \%$ confidence interval $(\mathrm{Cl})$. A significant $\mathrm{p}-\mathrm{value}$ was considered significant below 0.05 .

Table 3 Effect of residence on $\mathrm{t}(8: 21)$ generation and prenatal pesticides exposure in newborn

\begin{tabular}{|c|c|c|c|c|c|}
\hline Variables & Total $(\mathrm{N}=190)$ & Rural I 57 (83\%) & Urban 33 (17\%) & OR (95\% Cl) (P-value) & $\begin{array}{l}\text { *Adjusted } \\
\text { OR( } 95 \% \mathrm{Cl})(\text { P-value) }\end{array}$ \\
\hline $\begin{array}{l}\mathrm{t}(8 ; 2 \mathrm{I}) \\
\text { carriers } \\
\text { non carriers }\end{array}$ & $\begin{array}{l}38(20 \%) \\
152(80 \%)\end{array}$ & $\begin{array}{l}37(23.6 \%) \\
120(75.4 \%)\end{array}$ & $\begin{array}{l}\text { I }(3 \%) \\
32(97 \%)\end{array}$ & $\begin{array}{l}9.87(1.30-74.69) \\
0.027\end{array}$ & $\begin{array}{l}13.99(1.65-118.46) \\
0.015\end{array}$ \\
\hline $\begin{array}{l}\text { Malathion } \\
\text { Exposed } \\
\text { Non-exposed }\end{array}$ & $\begin{array}{l}77(41 \%) \\
113(59 \%)\end{array}$ & $\begin{array}{l}65(41.4 \%) \\
92(58.6 \%)\end{array}$ & $\begin{array}{l}12(36.4 \%) \\
21(63.6 \%)\end{array}$ & $\begin{array}{l}1.24(0.57-2.69) \\
0.592\end{array}$ & $\begin{array}{l}0.94(0.33-2.69) \\
0.909\end{array}$ \\
\hline $\begin{array}{l}\text { Diazinon } \\
\text { Exposed } \\
\text { Non-exposed }\end{array}$ & $\begin{array}{l}85(45 \%) \\
105(55 \%)\end{array}$ & $\begin{array}{l}68(43.3 \%) \\
89(56.7 \%)\end{array}$ & $\begin{array}{l}17(51.5 \%) \\
16(48.5 \%)\end{array}$ & $\begin{array}{l}0.72(0.34-1.56) \\
0.39\end{array}$ & $\begin{array}{l}0.56(024-1.29) \\
0.175\end{array}$ \\
\hline $\begin{array}{l}\text { DDT } \\
\text { Exposed } \\
\text { Non exposed }\end{array}$ & $\begin{array}{l}108(57 \%) \\
82(43 \%)\end{array}$ & $\begin{array}{l}92(58.6 \%) \\
65(41.4 \%)\end{array}$ & $\begin{array}{l}16(48.5 \%) \\
17(51.5 \%)\end{array}$ & $\begin{array}{l}1.5(0.7 I-3.20) \\
0.288\end{array}$ & $\begin{array}{l}1.72(0.63-4.67) \\
0.278\end{array}$ \\
\hline $\begin{array}{l}\text { Lindane } \\
\text { Exposed } \\
\text { Non exposed }\end{array}$ & $\begin{array}{l}95(50 \%) \\
95(50 \%)\end{array}$ & $\begin{array}{l}81(51.6 \%) \\
72(48.4 \%)\end{array}$ & $\begin{array}{l}14(42.4 \%) \\
19(57.6 \%)\end{array}$ & $\begin{array}{l}1.45(0.68-0.3 .09) \\
0.34\end{array}$ & $\begin{array}{l}1.25(0.42-3.66) \\
0.69\end{array}$ \\
\hline
\end{tabular}

Unconditional binary logistic regression for risk estimates was applied and presented as odds ratio (OR), $95 \%$ confidence interval (Cl).A significant p-value was considered significant below 0.05 * adjusted for pesticides exposure.

Citation: El Baz MA, El Deek SE, Sayed A, et al. In utero pesticides exposure and generation of acute myeloid leukemia associated translocation (8; 21$)$. MOJ Toxicol. 2016;2(3):54-60. DOI: 10.15406/mojt.2016.02.00037 
Table 4 Levels of pesticides in meconium $(\mu g / g)$ of $t(8 ; 2 \mathrm{I})$ carriers and non-carriers

\begin{tabular}{lllll}
\hline Pesticides & Total $(\mathbf{N}=1 \mathbf{9 0})$ & $\begin{array}{l}\mathbf{t}(\mathbf{8} ; \mathbf{2} I) \text { carriers } \\
\mathbf{( N = 3 8 )}\end{array}$ & $\begin{array}{l}\mathbf{t}(\mathbf{8} ; \mathbf{2} \mathbf{I}) \text { non-carriers } \\
\mathbf{( N = 1 5 2 )}\end{array}$ & P-value \\
\hline Malathion & $104.42(21.38)$ & $220.75(58.74)$ & $75.33(21.82)$ & $\leq 0.00 \mathrm{I}$ \\
Diazinon & $69.34(23.50)$ & $125.03(32.30)$ & $55.42(28.18)$ & 0.004 \\
DDT & $106.08(82.54)$ & $115.75(103.08)$ & $67.43(23.07)$ & $\leq 0.00 \mathrm{I}$ \\
Lindane & $21.86(3.72)$ & $42.22(11.84)$ & $16.78(3.49)$ & 0.042 \\
\hline
\end{tabular}

Pesticides were detected in meconium by GC-MS and presented as $\mu \mathrm{g} / \mathrm{g}$. Data are presented as mean and SEM, P value was calculated by Mann-Whitney $U$ test and was considered significant below 0.05 .

\section{Discussion}

This is a relatively large study that reported on the direct relation between Malathion and DDT exposure and the incidence of translocation $\mathrm{t}(8 ; 21)$ in apparently healthy neonates. This translocation is commonly seen in childhood AML; and to the best of our knowledge, our study is the first study to evaluate the effect of pesticides on acquiring such fusion Oncogene. The current study showed that prenatal exposure to Malathion and DDT are potentially implicated in the generation of $t(8 ; 21)$. Thirty eight $(20 \%)$ out of 190 neonates included in the current study were positive for the translocation of whom 60 and $80 \%$ were exposed in utero to Malathion and DDT respectively. As evidenced by detection of these pesticides in postpartum meconium, prenatal exposure to pesticides was higher, not only in terms of frequency but the levels were also higher in neonates carrying the translocation. Exposure to either Malathion or DDT increased the risk of harbouring the fusion Oncogene 3 times, and combined exposure raised the risk 7 folds. Malathion and DDT are well known genotoxic substances both on acute and chronic exposure in different cell lineages including cells of hematological origin as human T- lymphocytes. ${ }^{22,23}$ The genotoxic effects, including chromatid breakdown and increased the frequency of breakpoint formation, are noted at low concentration that did not even confer cytotoxicity; ${ }^{22-27}$ this explains the apparent healthy mothers and babies in our cohort. The absence of variation between $t$ $(8 ; 21)$ carriers and non-carriers regarding maternal and fetal variables (rather than being a rural resident) indicated direct association between exposure to theses pesticides and generation of the translocation. Being rural resident imparts 10 fold increased risk for $\mathrm{t}(8 ; 21)$ fusion Oncogene to form. Nevertheless, adjusted risk estimates showed that both Malathion and DDT exposure and rural residence were independent risk factors for the generation of fusion Oncogene, yet they potentiated each other's effect. As shown in Table 3 both rural and urban residents showed nearly the same frequency of exposure to pesticides. Still, within the rural group, those who were exposed to DDT and Malathion were more prone to carry the translocation. Consequently, the high rate of $\mathrm{t}(8 ; 21)$ carriers among rural residents could refer to certain untested environmental and/or socioeconomic characteristics. Other un-reported pesticides and mixed pesticides exposure could not be excluded. In fact, previous study by El-Baz et al. ${ }^{28}$ from the same locality reported around 9 different pesticides in the meconium of neonates. ${ }^{28}$ Only one- single study denoted the direct relationship between prenatal exposure to propoxur and the generation of $\mathrm{t}(8 ; 21)$, and described that $20 \%$ of the propoxur exposed neonates were positive for the translocation compared to $10 \%$ only in non-exposed. ${ }^{19}$ This is in accordance with our study in which around $30 \%$ of the neonates who were exposed to Malathion/ DDT were positive for the translocation. In communities with similar socioeconomic status to ours, being principally agricultural with growing urban regions, several retrospective studies reported increased risk of leukemia in children whose mothers were exposed to pesticides during pregnancy. ${ }^{13}$ For example, in a recent meta-analysis comprised 1,329 leukemia cases and 12,141 controls, Bailey et al described a doubled risk of childhood AML on maternal pesticides exposure during pregnancy. ${ }^{29}$ Ferreira et al. ${ }^{11}$ also indicated 3.5 fold increased risk for AML in Brazilian children, on maternal exposure to organophosphate at different time points of pregnancy. ${ }^{11}$ Similarly, Monge et al. ${ }^{12}$ suggested that parental exposure to Malathion among other pesticides may increase the risk of leukemia in the offspring born in Costa Rica. ${ }^{12}$ Besides previous studies that showed the presence of chromosomal rearrangements in archived neonatal heel-prick spots of children who later developed leukemia ${ }^{2,3,30}$ the present study supports the theory of its prenatal origin and presented a potential link of it to environmental toxins. The fusion Oncogene $t(8 ; 21)$ is described in normal population with prenatal origin at a frequency that exceeds the incidence of leukemia. Mori et al. ${ }^{31}$ reported that $5 \%$ of the newborn carry pre-leukemic translocations and this represents more than 100 fold the incidence of all types of leukemia $(1 / 2000) .{ }^{31}$ Notably, AML has incidence rate of $4 / 100.000^{32}$ and $t(8 ; 21)$ is reported in around $20 \%$ of AML cases before the age of $15 .{ }^{33}$ It is accepted that the presence of translocation alone is not sufficient to cause leukemia and additional genetic alteration and environmental hits are required to proceed to leukemia. However, the locality under study should be considered permissive for this $\mathrm{t}(8 ; 21)$ leukemia trait to develop into full leukemia cases. As this is mainly an agricultural community with low socioeconomic status and high rate of infection (a common second hit in leukemia pathology). ${ }^{4}$ Also, continuous postnatal pesticides exposure (an added risk) is expected in the community that presented neonates to such high level of pesticides prenatally. Accordingly, twenty percent $t(8 ; 21)$ traits in neonates of our study should undeniably be considered alarming. Since pediatric leukemia involves both genetics and environmental interactions, pesticides provide a perfect link in such regard. In this relatively large study we report on a direct relation of prenatal Malathion and DDT exposure and the incidence of leukemia translocation in neonates. Strict regulations on pesticides use are highly required especially in the developing countries. In these communities raising social awareness and providing protective tools would be highly effective on cutting down the exposure rate. Updated listing of carcinogenic pesticides, the acceptable exposure levels and the threshold at which these materials lead to genotoxic effect are awaited. This is a relatively large study that reported on the direct relation of Malathion and DDT exposure and the incidence of leukemia translocation in apparently healthy neonates. To the best of our knowledge, the current study is the first study to evaluate the effect of pesticides on acquiring AML fusion Oncogene in Egypt, where the analyzed Xenobiotics are still used and not banned yet. Meanwhile, Malathion which is a member of organophosphates is 
a commonly used pesticide for agriculture programmes. No studies were located regarding prenatal exposure to Malathion and generation of $t(8,21)$. The pesticide exposure rate was not based on history or questionnaire but on an accurate and sensitive GC-MS assay. The authors acknowledge lack of data on the duration and the window of time of pesticides exposure, lack of history of acute exposure of the mothers specially those living in rural areas, as well as history of paternal smoking and pesticide exposure that was collected from the mothers. Also the study did not follow up the carrier children. The follow up of those children knowing that they carry leukemogenic clones that may develop to leukemia on second hit (that could be modifiable risk) represented an ethical issue. Meanwhile, it would be a burden on the individual's, and family's life to know the fact of carrying leukemogenic trait.

\section{Acknowledgements}

None.

\section{Conflict of interest}

The author declares no conflict of interest.

\section{References}

1. Emerenciano M, Koifman S, Pombo de Oliveira MS. Acute leukemia in early childhood. Brazilian journal of medical and biological research. 2007;40(6):749-760.

2. Kempski H, Mensa Bonsu KA, Kearney L, et al. Prenatal chromosomal diversification of leukemia in monozygotic twins. Genes Chromosomes Cancer. 2003;37(4):406-411.

3. Maia AT, Ford AM, Jalali GR, et al. Molecular tracking of leukemogenesis in a triplet pregnancy. Blood. 2001;98(2):478-482.

4. Wiemels J. Perspectives on the causes of childhood leukemia. Chem Biol Interact. 2012;196(3):59-67.

5. Olesen LH, Clausen N, Dimitrijevic A, et al. Prospective application of a multiplex reverse transcription-polymerase chain reaction assay for the detection of balanced translocations in leukaemia: a single-laboratory study of 390 paediatric and adult patients. British journal of haematology. 2004;127(1):59-66.

6. Bhatia P, Binota J, Varma $\mathrm{N}$, et al. Incidence of Common Fusion Transcripts in Adult and Pediatric Acute Myeloid Leukemia (AML) Cases: Experience of a Tertiary Care Research institute. Mediterranean journal of hematology and infectious diseases. 2012;4(1):e2012042.

7. Lin $\mathrm{P}$, Chen $\mathrm{L}$, Luthra $\mathrm{R}$, et al. Acute myeloid leukemia harboring $\mathrm{t}$ $(8 ; 21)(\mathrm{q} 22 ; \mathrm{q} 22)$ : a heterogeneous disease with poor outcome in a subset of patients unrelated to secondary cytogenetic aberrations. Modern pathology. 2008;21(8):1029-1036.

8. Peterson LF, Zhang DE. The 8; 21 translocation in leukemogenesis. Oncogene. 2004;23(24):4255-4262.

9. Mc Hale CM, Smith MT. Prenatal origin of chromosomal translocations in acute childhood leukemia: implications and future directions. American journal of hematology. 2004;75(4):254-257.

10. Ma X, Buffler PA, Gunier RB, et al. Critical windows of exposure to household pesticides and risk of childhood leukemia. Environmental health perspectives. 2002;110(9):955-960.

11. Ferreira JD, Couto AC, Pombo-de-Oliveira MS, et al. In utero pesticide exposure and leukemia in Brazilian children $<2$ years of age. Environmental health perspectives. 2013;121(2):269-275.
12. Monge P, Wesseling C, Guaradado J, et al. Parental occupational exposure to pesticides and the risk of childhood leukemia in Costa Rica. Scand J Work Environ Health. 2007;33(4):293-303.

13. Kumar A, Vashist M, Rathee R. Maternal factors and risk of childhood leukemia. Asian Pacific journal of cancer prevention(APJCP). 2014;15(2):781-784

14. Calaf GM, Echiburu Chau C, Roy D. Organophosphorous pesticides and estrogen induce transformation of breast cells affecting p53 and c-Haras genes. International journal of oncology. 2009;35:1061-1068.

15. Koutros S, Sonja, Kathryn, et al. Genetic susceptibility loci, pesticide exposure and prostate Cancer Risk. PLOS ONE. 2013;8:e58195.

16. Schinasi L, Leon ME. Non-Hodgkin lymphoma and occupational exposure to agricultural pesticide chemical groups and active ingredients: a systematic review and meta-analysis. Int J Environ Res Public Health. 2014;11(4):4449-4527.

17. Bielawski D, Ostrea E, Posecion N, et al. Detection of Several Classes of Pesticides and Metabolites in Meconium by Gas Chromatography-Mass Spectrometry. Chromatographia. 2005;62(11-12):623-629.

18. Ostrea EM, Morales, Ngoumgna, et al. Prevalence of fetal exposure to environmental toxins as determined by meconium analysis. Neurotoxicology. 2002;23(3):329-339.

19. Lafiura KM, Bielawski DM, Posecion NC, et al. Association between prenatal pesticide exposures and the generation of leukemia-associated T(8;21). Pediatric blood \& cancer. 2007;49(5):624-628.

20. Abo EL MaaliN, Wahman AY. Gas Chromatography-Mass Spectrometric Method For Simultaneous Separation and Determination of Several POPs with Health Hazards Effects. Mod Chem appl. 2015;3:167.

21. vanDongen JJ, Macintyre, Gabert, et al. Standardized RT-PCR analysis of fusion gene transcripts from chromosome aberrations in acute leukemia for detection of minimal residual disease. Report of the BIOMED-1 Concerted Action:investigation of minimal residual disease in acute leukemia. Leukemia. 1999;13(2):1901-1928.

22. Armbruster DA, Tillman MD, Hubbs LM. Limit of detection (LQD)/ limit of quantitation (LOQ): comparison of the empirical and the statistical methods exemplified with GC-MS assays of abused drugs. Clinical chemistry. 1994;40(7):1233-1238.

23. Pluth JM, Nicklas JA, O'Neill JP, et al. Increased frequency of specific genomic deletions resulting from in vitro malathion exposure. Cancer research. 1996;56:2393-2399.

24. Pluth JM, O Neill JP, Nicklas JA, et al. Molecular bases of hprt mutations in malathion-treated human T-lymphocytes. Mutat Res. 1998;397(2):137-148.

25. Canales Aguirre A, Padilla Camberos E, Gomez Pinedo U, et al. Genotoxic effect of chronic exposure to DDT on lymphocytes, oral mucosa and breast cells of female rats. International journal of environmental research and public health. 2011;8(2):540-553.

26. Garaj Vrhovac V, Gajski G, Ravlic S. Efficacy of HUMN criteria for scoring the micronucleus assay in human lymphocytes exposed to a low concentration of p,p'-DDT. Brazilian journal of medical and biological research. 2008;41(6):473-476.

27. Moore PD, Patlolla AK, Tchounwou PB. Cytogenetic evaluation of malathion-induced toxicity in Sprague-Dawley rats. Mutat Res. 2011;725(1-2):78-82.

28. El Baz MAH, El Deek SEM, Nsar AY, et al. Prenatal Pesticide Exposure: Meconium as a Biomarker and Impact on Fetal Weight. J Environ Anal Toxicol. 2015;5:268. 
29. Bailey HD, Fritschi L, Infante Rivard C, et al. Parental occupational pesticide exposure and the risk of childhood leukemia in the offspring:findings from the childhood leukemia international consortium. Int J Cancer. 2014;135(9):2157-2172.

30. Wiemels JL. In utero origin of $\mathrm{t}(8 ; 21)$ AML1-ETO translocations in childhood acute myeloid leukemia. Blood. 2002;99(10):3801-3805.

31. Mori H. Chromosome translocations and covert leukemic clones are generated during normal fetal development. Proc Natl Acad Sci USA. 2002;9(12):8242-8247.
32. Deschler B, Lubbert M. Acute myeloid leukemia: epidemiology and etiology. Cancer. 2006;107(9):2099-2107.

33. Reikvam H, Hatfield KJ, Kittang AO, et al. Acute myeloid leukemia with the $\mathrm{t}(8$; translocation: clinical consequences and biological implications. Journal of biomedicine \& biotechnology. 2011;2011(2011):1-23. 